\title{
Variations in geoacoustic emissions in a deep borehole and its correlation with seismicity
}

\author{
Valery Gavrilov ( $\left.{ }^{1}\right)$, Leonid Bogomolov $\left({ }^{2}\right)$, Yulia Morozova $\left({ }^{1}\right)$ and Aleksander Storcheus $\left({ }^{1}\right)$ \\ (') Institute of Volcanology and Seismology, Far East Branch of the Russian Academy of Science, \\ Petropavlovsk-Kamchatsky, Russia \\ ${ }^{(2)}$ Institute of Marine Geology and Geophysics Far East Branch, of the Russian Academy of Science, \\ Yuzhno-Sakhalinsk, Russia
}

\begin{abstract}
Continuous geoacoustic emission (GAE) measurements were acquired using a three-component geophone placed in a borehole at a depth of near $1000 \mathrm{~m}$ at Petropavlovsk-Kamchatsky starting in August 2000. Using geophones consisting of magneto-elastic crystal ferromagnetic sensors, and installed at such a depth allows measurement of natural geoacoustic background with signal amplitude less than $1 \times 10^{-4} \mathrm{~m} / \mathrm{s}^{3}$ in frequency band from 3 to $1500 \mathrm{~Hz}$. According to the data from a 4-year survey period the characteristics of diurnal geoacoustic variations change before every earthquake with $\mathrm{M}_{\mathrm{LH}} \geq 5.0$ that occurs at a distance of less than $300 \mathrm{~km}$ from the observation point or before each earthquake with $\mathrm{M}_{\mathrm{LH}} \geq 5.5$ occurring at distance $\mathrm{R} \leq 550 \mathrm{~km}$ from the observation point. The changes in GAE regime correlate with the strongest earthquakes that occurred during survey period. Measurements of the natural electromagnetic field of the Earth were carried out simultaneously with the help of an underground electric antenna. The behavior of GAE in aseismic periods appears to be related to the effect of diurnal variations of the natural electromagnetic field.
\end{abstract}

Key words geoacoustic emission - deep borehole, diurnal variation - earthquake occurrence - natural electric field

\section{Introduction}

The concepts of cracking within heterogeneous media are the fundamental to modern models of earthquake preparation and source site formation. As indicators of micro-fracturing processes such as cracking, shifts along blocks boundaries, pore coalescence, changes in interstitial fluid pressure etc., spatio-temporal characteristics of acoustic emission (AE) con-

Mailing address: Dr. Leonid Bogomolov, Institute of Marine Geology and Geophysics of the Russian Academy of Science, Nauki str., 1 B, 693022, Yuzhno-Sakhalinsk, Russia tribute to validation and/or improvement of such models. This equally involves the results of laboratory-scale experiments on rock specimens to simulate tectonic straining processes, and geoacoustic emission (GAE) surveys (seismoacoustics, by other term (Belyakov et al., 1996)) aimed to study natural acoustic emission of embedded rocks.

The results on GAE variations recorded in a tunnel at $100 \mathrm{~m}$ depth (Matsushiro seismological observatory, prefecture Nagano, Japan) were represented in (Gorbatikov et al., 2001). The measurements were carried out with the help of three-component MAG-3S geophone designed at Earth Physics Institute of the Russian Academy of Sciences on the basis of magneto-elastic sensor (Belyakov, 2000). The output signal of such sensor is proportional to the third derivative of the ground displacement, and the gain slope of MAG-3S geophone is equal to $60 \mathrm{Db}$ 
for a decade of frequency change. Such characteristics allow measurement of GAE natural background with minimal amplitude of signals (evaluated as equivalent ground displacement) less than $1 \times 10^{-10} \mathrm{~m}$. According to the results of (Gorbatikov et al., 2001) some increase in GAE level has been recorded in 5 cases of earthquakes with $\mathrm{M}=3.7 \div 5.2$ that occurred at epicentral distances up to $110 \mathrm{~km}$. The observed variations occurred nearly 12 hours before the events. These results demonstrate that geoacoustic measurements using high-sensitivity geophones (Belyakov et al., 1999) are able to provide new significant information and put some light on the earthquake preparation process. Until now most surveys have been conducted in seismically inactive regions.

Interesting results related to GAE measurements with a geophone have been revealed recently in works (Cuomo et al., 2000; Gregori et al., 2002; Paparo et al., 2002), where another approach has been developed with a similar purpose: to distinguish signals originated by stressed-strained crust from the background of extraneous noise. The authors (Cuomo et al., 2000; Gregori et al., 2002; Paparo et al., 2002) argued that ultrasonic acoustic emission measurements of the Earth surface can be a diagnostic tool for changes in crust stress in seismic areas. This is possible provided that the sensors are installed on bedrock outcroppings, and acoustic emission signals are recorded in the ultrasonic frequency range $(10-200 \mathrm{kHz})$ higher than usual frequencies of GAE measurements. According to (Paparo et al., 2002) bedrocks from top to bottom can play a role of a giant probe, so that $\mathrm{AE}$ signals recorded on the outcrop are sensitive to variations of tectonic stress and are relevant to seismic processes. Although ultrasonic signals are not able to extend to large distances, anomalies of AE flow before strong earthquakes have been revealed during AE measurements in Apennines, Italy (Cuomo et al., 2000; Gregori et al., 2002; Paparo et al., 2002).

The existence of distinct diurnal variations of GAE level in the frequency range 10-200 $\mathrm{kHz}$ and their interrelations with changes in natural electric field strength follow from data given by (Paparo et al., 2002). Diurnal varia- tions of GAE level were also recorded (but in frequency range $30-1200 \mathrm{~Hz}$ ) when the geoacoustic surveys were carried out with the help of MAG -3S geophones installed in boreholes (Belyakov et al., 1999). Sensor allocation inside deep enough boreholes $(700 \mathrm{~m}$ depth or more) where the level of geoacoustic emission is controlled by natural crust (lithospheric) processes is a proper way to provide necessary sensitivity of GAE measurements. Unfortunately the results represented in (Belyakov et al., 1999) were obtained mainly by measurements in seismically inactive regions and therefore do not reveal cause-and-effect relations of characteristics of geoacoustic emissions with stressed-strained state of a terrestrial crust.

This paper is devoted to the results of the continuous geoacoustic measurements performed in 2000-2003 in the seismically active region of Kamchatka, Russia, with the use of MAG-3S geophone, installed inside a deep G-1 borehole at the depth of $1035 \mathrm{~m}$. Some preliminary results of these measurements were described in (Gavrilov et al., 2006; Gavrilov, 2007). Hereinafter we analyze the results of geoacoustic measurements together with the data of seismicity of Southern and Central parts of Kamchatka.

\section{Equipment and observation technique}

The station for GAE measurements was built on the base of the G-1 borehole (Lat. 53.05 N, Long. 158.63 E) located in Petropavlovsk-Kamchatsky, a zone of deep northwest oriented fault. The depth of the borehole is $2540 \mathrm{~m}$. The borehole is water-filled and cased along the whole length. The structure of the measuring system is presented in fig. 1 . The geophone, which is the main measuring unit of the system, was installed at a $1035 \mathrm{~m}$ depth. The body of the sensor is crowded against the casing by a spring.

The sensitivity of the vertical channel of the geophone (evaluated on preliminary amplifier output) is $0.15 \mathrm{~V} \times \mathrm{s}^{3} / \mathrm{m}$, and the resonant frequency of the sensor is $1250 \mathrm{~Hz}$. The sensitivity of the horizontal channels is $0.60 \mathrm{~V} \times \mathrm{s}^{3} / \mathrm{m}$, the resonant frequency being $300 \mathrm{~Hz}$. The output signals of geophone pre-amplifiers are trans- 


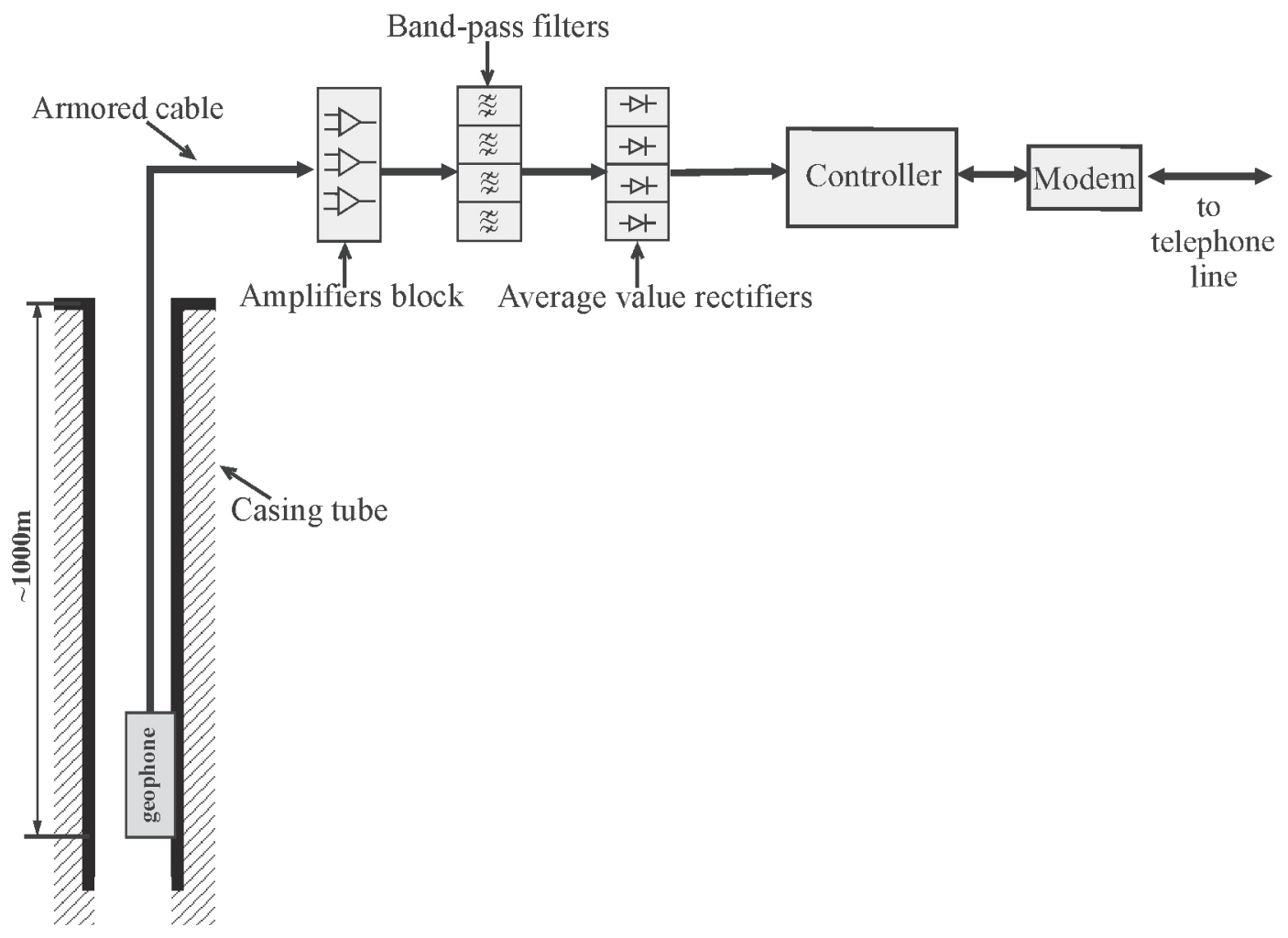

Fig. 1. The structure of measuring complex.

ferred through armored cable to the main processing unit, located at the mouth of the well. The main analog unit provides additional amplification, subsequent filtering of the initial signals of each geophone channel by a third octave band pass filter, distinguishing the bands with the four central frequencies chosen: 30, 160,560 and $1200 \mathrm{~Hz}$, and, finally, the measurement of averaged values of output filtered and rectified signals (from each of 12 filters). The further processing of signals is realized with the help of the microprocessor controller. The functions of the microcontroller involve analog-digital converting of the input analog signals (the sampling rate is $32 \mathrm{~Hz}$ on the channel), calculation of average values of recorded signals in one minute moving window, and, finally, data saving on the disk memory. The data are transferred via telephone channel to the
Data Management Center of the Institute of Volcanology and Seismology, Far East Branch of the Russian Academy of Sciences, Petropavlovsk-Kamchatsky, on request of the operator.

\subsection{GAE level dependence on depth and borehole $\log$}

Before geophone installation at a permanent depth $1035 \mathrm{~m}$, measurements of GAE level were performed on various minor depths (fig. $2)$. At $200 \mathrm{~m}$ depth the level of noise in frequency bands 30 and $160 \mathrm{~Hz}$ dropped approximately by $17-20 \mathrm{~dB}$ (7-10 times) compared to that on the original ground. Subsequent deepening of the geophone up to $600 \mathrm{~m}$ depth was followed by smooth damping of the noise in the noted bands: it decreased by $10-13 \mathrm{~dB}$ com- 
pared to that at $200 \mathrm{~m}$ depth (in the band nearly $30 \mathrm{~Hz}$ ). A sharp decrease of GAE level in low frequency bands at shallow depths was predetermined by contribution of man-made noise produced at the daylight surface. The bands with central frequencies 30 and $160 \mathrm{~Hz}$ were close to urban frequencies. Man-made noise at frequencies 560 and $1200 \mathrm{~Hz}$ was less, and it did not contribute to GAE levels even at shallow depths of 100-200 m. Correspondingly, only slight decreases in GAE levels were observed at higher frequency bands (560 and 1200 $\mathrm{Hz})$. Significant increases of GAE levels in all frequency bands occurred in the interval of 600 to $900 \mathrm{~m}$ depth. The greatest increment of noise $(12-13 \mathrm{~dB})$ was denoted in the bands 30 and $160 \mathrm{~Hz}$. Subsequent geophone embedding to $1035 \mathrm{~m}$ depth resulted in a decrease in noise levels for all bands.

The non-trivial observation that GAE amplitudes increase in all frequency bands in the layer of 700-900 m depth and decrease sharply from 900-1035 m may be related to peculiar features of the geologic profile at the borehole site. The G-1 borehole is located in a small valley with rocky edges. According to the geological cross-section, the valley bed is filled up to $80 \mathrm{~m}$ depth by sandy-argillaceous deposits with inclusions of pyroclastic strata. The layer from 80 to $110 \mathrm{~m}$ depth is formed by siltstones and sandstones stratigraphically alternated by clay interlayers. Denser slates of uniform makeup occur at depths more than $110 \mathrm{~m}$. According to the cross-section, the rocks lying at depths from 520 to $840 \mathrm{~m}$ are characterized by horizontal schistosity. There are four explicit layers on this interval of depth (fig. 2), each layer being of 50-100 m thick. Hydrothermal veins with pyrite and calcite are represented widely at depths from 650 to $740 \mathrm{~m}$. This is dissimilar to only one layer occurring at depth between 100 and $520 \mathrm{~m}$. The rocks lying at 820-1035 $\mathrm{m}$ depth

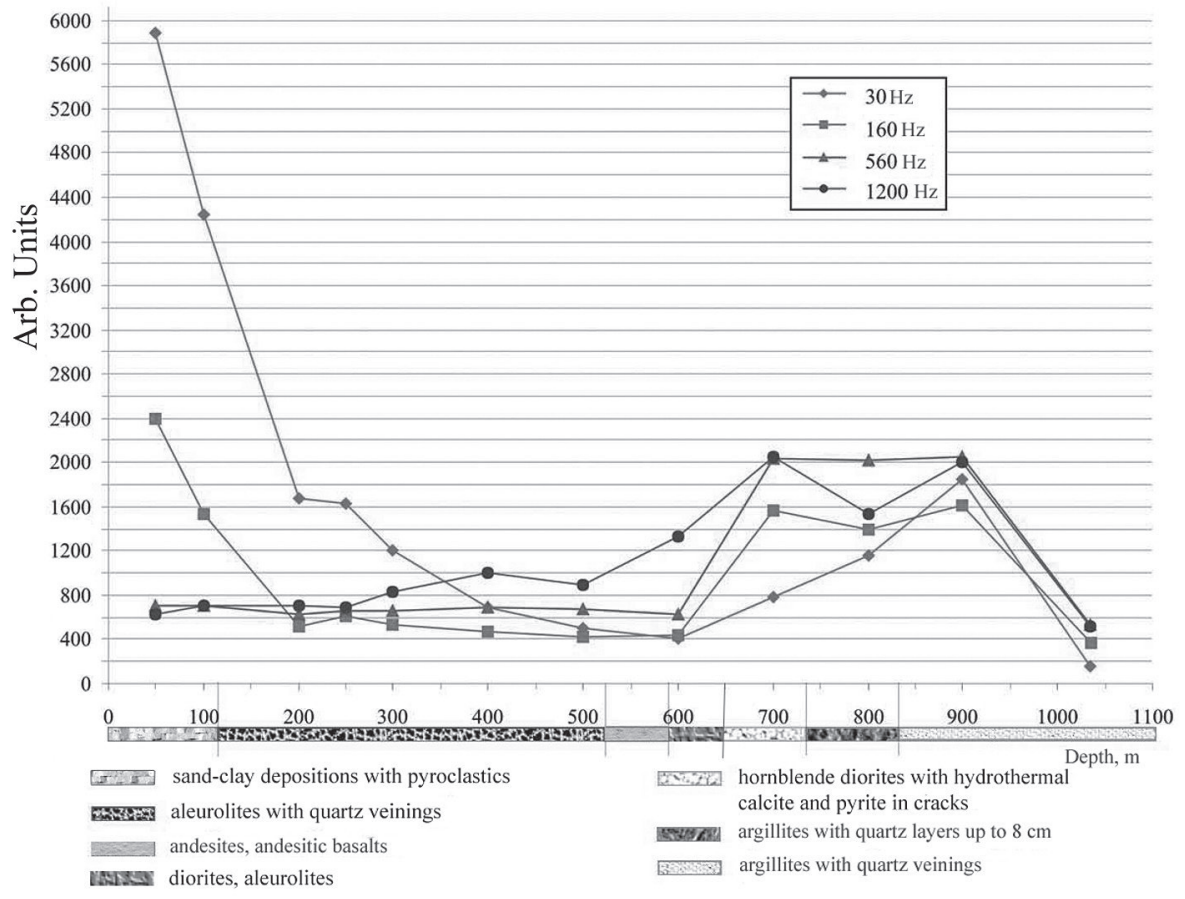

Fig. 2. The dependence of mean GAE level at several frequency bands on depth of geophone location. GAE signals horizontal component has been plotted. 
represent the single strata as well. Presumably, the rocks of enhanced stratification, with softened inclusions at the bedding interface, cause enhanced dynamic and geoacoustic activity at that depth (the more contacting surfaces, the more microscopic shifts). Some results of geoacoustic surveys in other regions (Belyakov et al., 1996, 1999) may confirm this reasoning on stratification and heterogeneity (the cause of seeming crust anelasticity). All this may explain, to a certain extent, the maximal value of GAE level found at depths in the middle of interval $600-900 \mathrm{~m}$. Apart from the schistosity interval (both upwards and downwards) the level of GAE drops.

Certainly, the data on vertical dependence of GAE indicate that the layer of depth from 700 to $900 \mathrm{~m}$ is the most preferred for permanent measurements with the geophone (rather than its actual location at the $1035 \mathrm{~m}$ horizon). However these data (summarized in the fig. 2) were obtained after the geophone installed at $1035 \mathrm{~m}$ depth. Thereafter, because of technical reasons, we had no opportunity to change the position of the geophone. The main methodical result of GAE amplitude vertical scanning (fig. 2 ) is direct proof that geophone installation inside the borehole at near $1000 \mathrm{~m}$ depth greatly reduces low frequency exogenous noise (30 and $160 \mathrm{~Hz}$ bands). The level of noise reduced by $40 \mathrm{~dB}$ (two orders of value) at $30 \mathrm{~Hz}$ frequency, and also reduced by $17 \mathrm{~dB}$ (nearly order) at 160 $\mathrm{Hz}$ frequency, both cases in comparison with level of noise on original ground.

\subsection{Influence of meteorological factors}

Comparisons of GAE variations with changes in atmospheric pressure, air temperature and speed of wind revealed no appreciable correlation. A possible influence of rain on measurements on the vertical channel was noted in two of 24 cases. In the first case, the rainfall was about $20 \mathrm{~mm}$ in a day, in the second - about $50 \mathrm{~mm}$ in a day.

The effect of precipitations appeared in the form of 20-30\% bay-like increases in average level of noise which were delayed of 12-15 hours after the beginning of rain and terminated simultaneously with it or some hours later. The records of horizontal channels were never influenced by raining.

Snowfalls exerted a stronger influence upon variations of GAE level on horizontal channels that has been confirmed by observation of the effect in 11 of 13 cases. The effect of snow falloff appeared as 50-100 \% increase in average noise level on horizontal channels, usually starting in 12-15 hours after the beginning of snowfall and ending in 3-12 hours after snowfall stopped. The most apparent effect of precipitations occurred during strong snowfalls when the daily accumulation of snow was 30-60 mm (fig. 3). Sometimes, a delayed noise was noted even when the snowfall did not exceed 10-15 mm per day. Interestingly, the data from the vertical channel never showed the effect of snowfall on the GAE.

The effect of precipitations on GAE measurements can be explained based on the following model, which appeals to the geological structure of the valley. It was already mentioned that sediments of the uppermost layer (above $110 \mathrm{~m}$ depth) are not so consolidated as slate-like rocks situated below $110 \mathrm{~m}$. Snow precipitations resuls in additional weight, and this is the reason for some extra compaction of sediments at shallow depths in territory of the valley. Simple calculations show that a 30 -mm-thick snow layer (the case of observed correlation with GAE) may produce additional pressure of nearly $300 \mathrm{~Pa}$. The lithostatic pressure at a depth of a few hundred meters is in the order of $2-5 \mathrm{MPa}$, in which the lowest estimate is given for the $110 \mathrm{~m}$ depth, i.e. the bottom of the uppermost layer. The ratio of additional pressure to lithostatic one is equal approximately to $10^{-4}$, and the relative change in uppermost layer strain is of the same value. We note that a typical value of Young modulus of upper sediments (occurred in this layer) is of the order of $10^{10} \mathrm{~Pa}$, (Scheidegger, 1975). Using this value we may estimate the increment of absolute strain at $110 \mathrm{~m}$ depth, caused by weight of 30 -mm-thick snow layer, as $3 \times 10^{-8}$. Meanwhile, lunar-solar tides are characterized by a $10^{-8}$ change in strain components (as noted in work (Diakonov et al., 1990) for latitude 40-50 degrees). According to a well known hypothesis (Rykunov and Smirnov, 1985; Diakonov et al., 


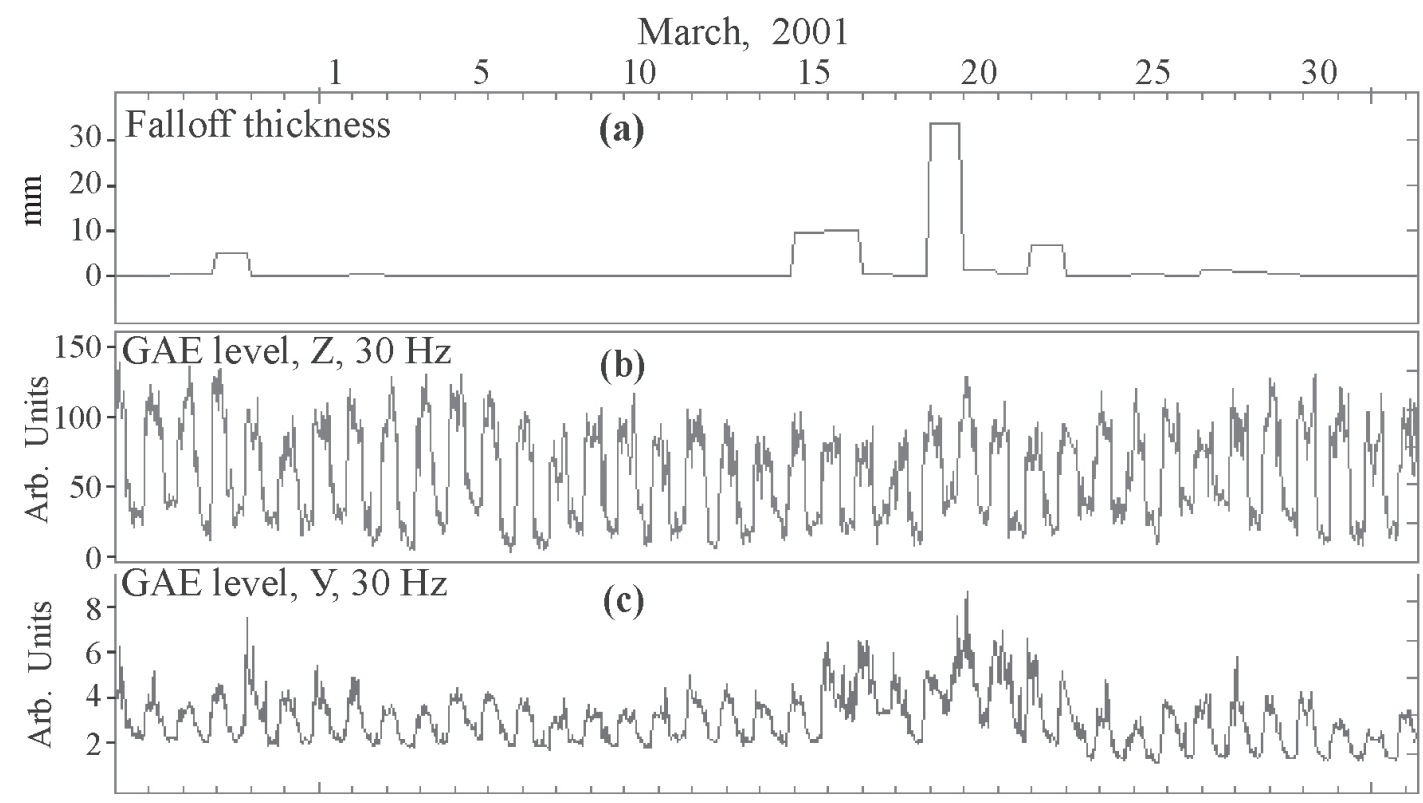

Fig. 3a-c. Episodic influence of snow falloff on results of GAE measurements: a) daily accumulation of snow, b) temporal dependence of vertical component GAE level, $30 \mathrm{~Hz}$ central frequency; c) the same for horizontal component.

1990), the tides have potential to trigger some fault slips, as well as geoacoustic emissions, since the rate of tidal stress is high enough with respect to a tectonic stress. The growth of additional strain during an intensive snowfall is still more rapid than that in the case of tides. Actually, a snow accumulation of 30-mm-thick layer may occur in few hours, and the strain rate reaches the value $3 \times 10^{-12} 1 / \mathrm{s}$. The rate of tidal strains was estimated as $1-3 \times 10^{-12} 1 / \mathrm{s}$. So, the change in the uppermost layer strain, caused by snow falloff, may have some influence on inelastic processes (similarly to the case of solar-lunar tides).

The effect is probably amplified due to a structural factor. Edges of the valley are steeply inclined, although not vertical in the cross-section. The compaction of the upper sedimentary layer inside a limited area may cause a portion of the horizontal stress to act normally to the surface of the casing tube. The contact of the casing and the adjacent rock becomes more or less strong. The receiving condition of GAE of horizontal component (normal to contact sur- face) is very sensitive to contact state changes. Rain precipitations have practically no effect on the results of GAE measurements, because the water goes away quickly. Hence, minor increment of weight after raining together with the short term action of water weight may induce only weak perturbation in comparison with the case of snow precipitation.

So, the change in GAE level on horizontal channel is expected to correlate to temporal variations of normally acting force (horizontal pressure). The correlation has a lag of 12-15 hours after accumulation of snow precipitations. Actually such a lag is a transition time during which pressure change transforms to plastic strain wave and propagates along the casing tube towards horizon of geophone location. The vertical channel of GAE is not affected by this mechanism, since receiving condition for GAE shearing component is not so sensitive.

According to the mentioned observations and their interpreting, the GAE data from horizontal channels have been distorted by exogenous inter- 
ferences to a greater extent than that from the vertical channels. For this reason, only measurements of the vertical component of GAE signals (i.e. the data from the vertical channel) have been used below in this paper, as outlined below.

\section{Results of continuous GAE surveys at the $1035 \mathrm{~m}$ depth}

Continuous GAE measurements started in August 2000. In this section we consider peculiar features of temporal dependences of geoacoustic emission obtained by continuous surveys during August 5, 2000 to July 31, 2003. During primary data analysis we focused on manifestations of characteristic diurnal variations of averaged GAE levels. Characteristic variations constitute diurnal geoacoustic emission distributions (DGAED) of 24 hours periodicity which usually emerge in aseismic periods (Gavrilov et al., 2006).

An especially developed PC program has been used to establish the presence or absence of DGAED in GAE time series from August 5, 2000 to July 31, 2003. Sometimes a simple visualization of these time series (plotted output) can reveal diurnal variations. The program of the GAE time series processing is based on «recognition» of the GAE variations similar to logistic function of sunrise/sunset $\mathrm{g}$ (t), so-called meander (trial rectangular increment). The function $g(t)$ is equal to 1 (unity) when the Sun is above the horizon, and it is -1 after a sunset. The algorithm of recognition involves the selection of such coefficients of regression $a$ and $b$, to minimize the regression function (below) in the given time window

$$
R=\sum_{i}\left(f\left(t_{i}\right)-a g\left(t_{i}\right)-b\right)^{2},
$$

where $f\left(t_{i}\right)$ - current value of GAE level, $t$ - time.

Coefficients $a$ and $b$ can be determined from system of the equations:

$$
\begin{gathered}
\frac{\partial R}{\partial a}=2 \overline{a g^{2}}-2 \overline{f g}+2 \overline{b g}=0 ; \\
\frac{\partial R}{\partial b}=2 b-\overline{2 f}+2 \overline{a g}=0 ;
\end{gathered}
$$

where the lines above variables or expressions note their averaging over time window.

As result of the solving system of the equations (3.2) one can receive:

$$
a=\frac{\overline{f g}-\bar{f} \cdot \bar{g}}{1-\bar{g}^{2}} ; \quad b=\frac{\bar{f}-\overline{f g} \cdot \bar{g}}{1-\bar{g}^{2}}
$$

This means that the coefficient $a$ is the averaged amplitude of DGAED, whereas $b$ is the daily average level of GAE. Coefficients $a$ and $b$ concern to data on entire window (all $\mathrm{n}$ counts of function $\left.f\left(t_{i}\right)\right)$.

We have selected a two-day window ( $\mathrm{n}=$ 2880) for computations by the outlined algorithm. Transition intervals of $30 \mathrm{~min}$ length close to the estimated times of Sun rising and a sunset have been excluded from the analysis. The exceeding of the threshold value $a_{c}$ of 500 relative units (RU) by the average amplitude of DGAED has been considered as a criterion for the presence of GAE diurnal distribution provided that the maximal value of DGAED amplitude was equal to $a_{\max }$ of $2804 \mathrm{RU}$.

The result of computations is that the characteristic diurnal variations have been distinguished in GAE time series during approximately $60 \%$ of observation time. An example of such variations in temporal intervals during August 13-16, 2001 and September 3-7, 2001 is presented on fig. 4a and $4 \mathrm{~b}$ (Greenwich time is hereafter used). Transition times from the minimum values of emission level to the maximal one and vice versa are about 5-10 minutes. The moments of transitions correspond to the times of terminator line crossing (times of sunset and sunrise) at the observation point. The most explicit diurnal variations (day time minimum and nocturnal maximum) have been revealed on GAE series recorded by channels for vertical components, with the central frequencies of $30 \mathrm{~Hz}$ and $160 \mathrm{~Hz}$.

\subsection{The changes in GAE characteristics related to the preparation of earthquakes}

As a rule, considerable perturbations of the diurnal GAE distributions (DGAED) have been observed before earthquakes $\mathrm{M}_{\mathrm{LH}} \geq 5.0$ in the 


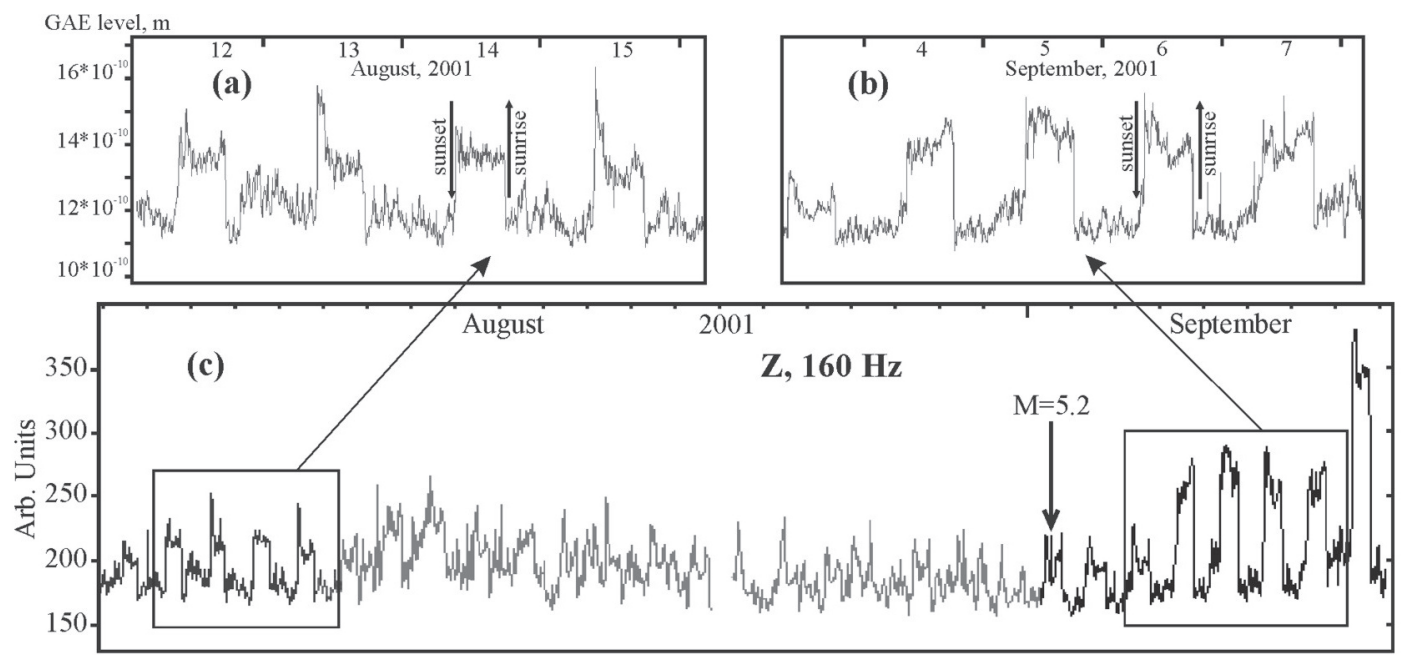

Fig. 4a-c. A plot of characteristic diurnal variations of mean geoacoustic emission level (for $\mathrm{Z}$ component of GAE signals in a band with central frequency of $160 \mathrm{~Hz}$ ). The Greenwich time is noted on time axis.

area of the Kamchatkan subduction zone. Typical examples of such perturbations prior to the earthquakes are presented in figs. 4c and fig. 5.

Figure $4 \mathrm{c}$ shows the disturbance of DGAED before an $\mathrm{M}_{\mathrm{LH}}=5.2$ earthquake, which occurred on September 1, 2001, $120 \mathrm{~km}$ to the northeast from the observation point. In this case the diurnal GAE distributions, which appear to be normal during August 12-16, 2001, are conspicuously distorted (almost disappeared) during August 17-31, 2001. The DGAED return to the normal form soon after the earthquake.
Prior to the seismic swarm in October 2002, which occurred $170 \mathrm{~km}$ to the south of Petropavlovsk-Kamchatsky, the DGAED disappeared seven days prior to the first shock (fig. 6). Until this moment, a steady diurnal distribution was observed during about three months. Being typical for aseismic periods, GAE day night variations restored a day after the strongest $\left(\mathrm{M}_{\mathrm{LH}}=5.7\right)$ earthquake of the swarm.

According to the catalog of earthquakes of the Geophysical Service of the Russian Academy of Science, 56 earthquakes $\mathrm{M}_{\mathrm{LH}} \geq 5.0$ in-

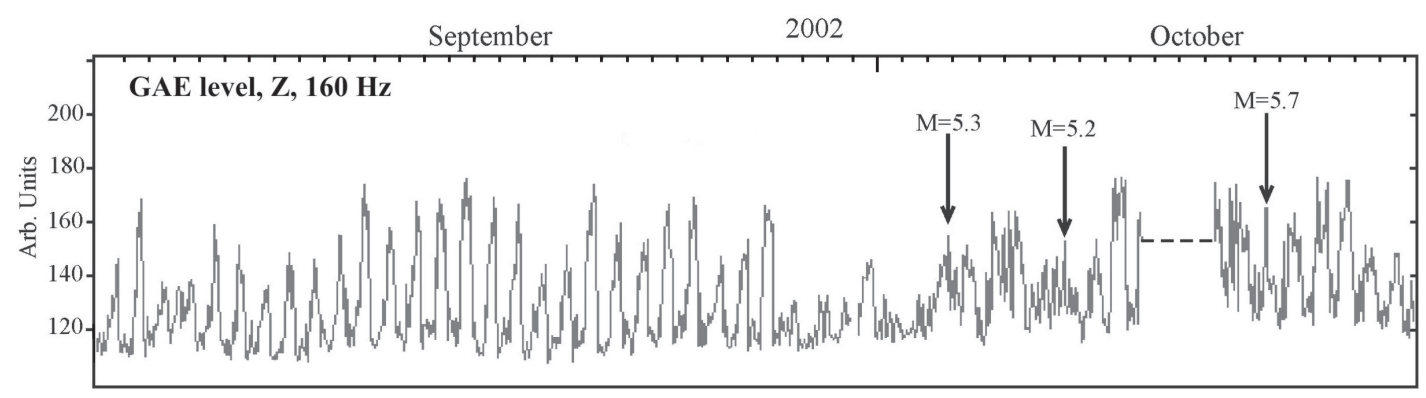

Fig. 5. Examples of loss of diurnal GAE distributions (DGAED) prior to the occurrence of earthquakes. 


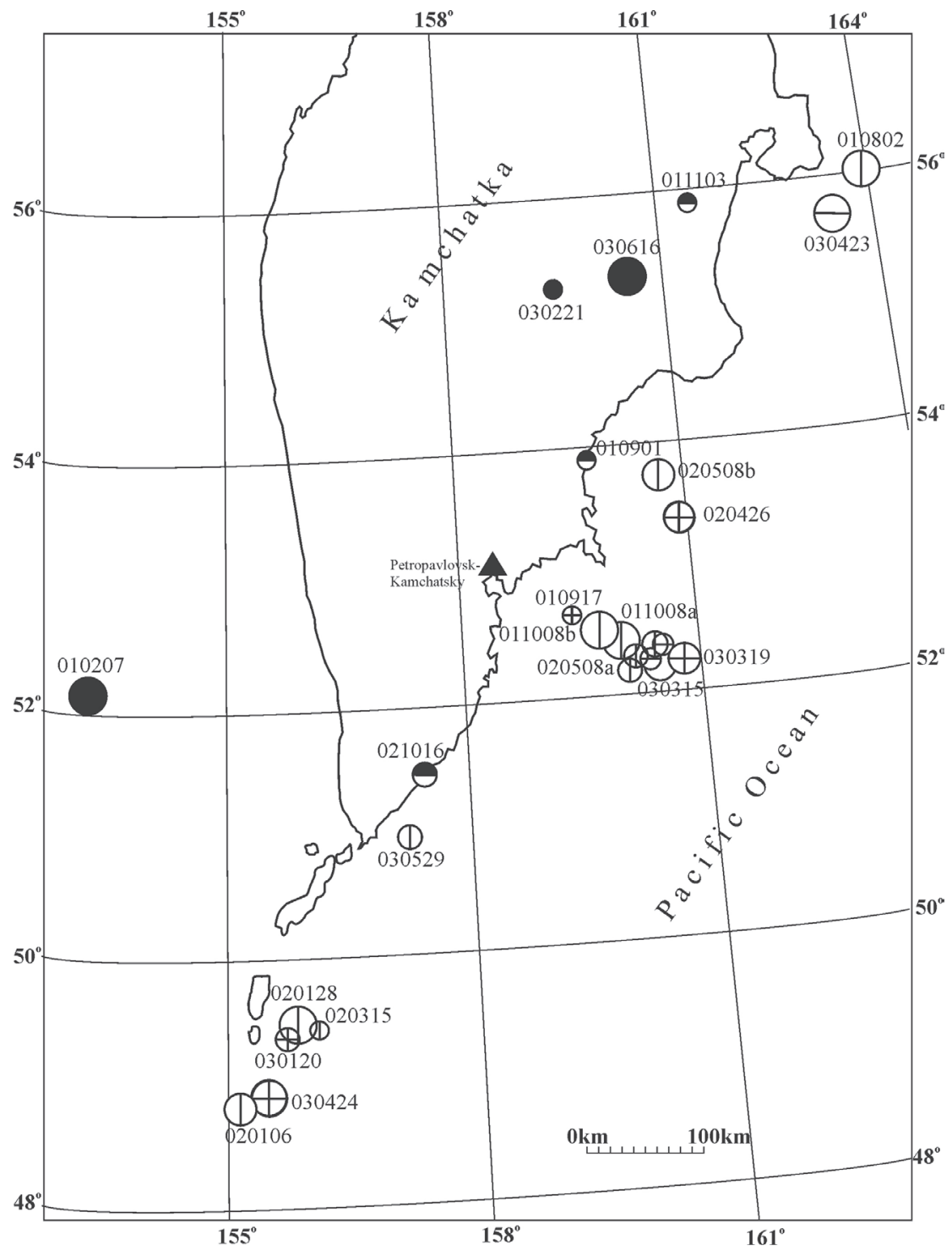

Depth of earthguakes, $\mathrm{km}$

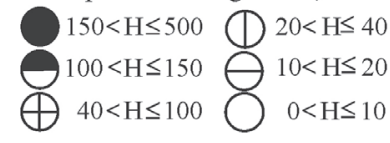

Magnitudes of earthguakes $\mathrm{M}_{\mathrm{LH}}$ :

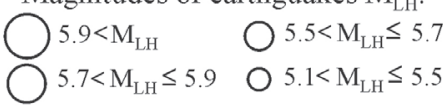

borehole G1

Fig. 6. Mapping of epicenters of earthquakes occurred during the period January 1, 2001- July 31, 2003 in zone $\mathrm{R} \leq 300 \mathrm{~km}$, centered at Petropavlovsk -Kamchatsky (events of $\mathrm{M}_{\mathrm{LH}} \geq 5.0$ magnitude), and in zone $\mathrm{R} \leq 550 \mathrm{~km}$ (events of $\mathrm{M}_{\mathrm{LH}} \geq 5.5$ magnitude). 
cluding aftershocks of strong earthquakes occurred within $550 \mathrm{~km}$ in distance from Petropavlovsk-Kamchatsky during August 1, 2000 - July 31, 2003. A subsample of 36 seismic events was selected and used for analysis, taking into account 15 earthquakes of magnitude $\mathrm{M}_{\mathrm{LH}} \geq 5.0$, occurred in near-field zone (inside a circle of $\mathrm{R} \leq 300 \mathrm{~km}$ radius) and 21 earthquakes of major magnitude $\left(\mathrm{M}_{\mathrm{LH}} \geq 5.5\right)$, with epicenters located in circular zone $\mathrm{R} \leq 550 \mathrm{~km}$. Parameters of these earthquakes are given in table I and locations of epicenters are shown on fig. 6. The strongest $\mathrm{M}_{\mathrm{W}}=7.3$ earthquake during the last five years that occurred on November 17, 2002, at $459 \mathrm{~km}$ depth is also presented in table I. The epicenter of the earthquake was located in the Okhotsk Sea at $1000 \mathrm{~km}$ from the point of observation.

Figure 7 compares periods of DGAED presence or absence with exact times of occurred earthquakes. It is shown that earthquakes mostly occur during periods without characteristic diurnal variations. This includes an example of rather short interval ( 24 hours) without characteristic diurnal variations, for which earthquake of August 2, 2001 occurred. Not every episode of disorder of GAE diurnal distribution was followed by an earthquake (as shown in fig. 7). Meanwhile, the disturbances of DGAED (full disappearance or degradation) occurred before all 15 earthquakes of magnitude $\mathrm{M}_{\mathrm{LH}} \geq 5.0$ inside circular zone around point of observation, of $300 \mathrm{~km}$ radius. Also, such disorders occurred before all 21 strong earthquakes, $\mathrm{M}_{\mathrm{LH}} \geq 5.5$ whose epicenters located at distances less than $550 \mathrm{~km}$ from the geophone point. The same is valid for the case of the strongest $\mathrm{M}_{\mathrm{W}}=7.3$ earthquake that occurred on November 17, 2002 at $1000 \mathrm{~km}$ epicentral distance.

So, the disorder of diurnal variation may be considered a necessary but not sufficient condition of a forthcoming earthquake. Our measurements at the single point give no result on prediction of place of shock. But the most important consequence of the observations is that during a period of regular diurnal variations in GAE (lasting 7 days or more) no earthquake is expected as long as a disorder of the DGAED is to occur. Below we consider statistical aspects of a relationship between times of strong earthquakes occurrence and cases of the DGAED disorder/restoration.
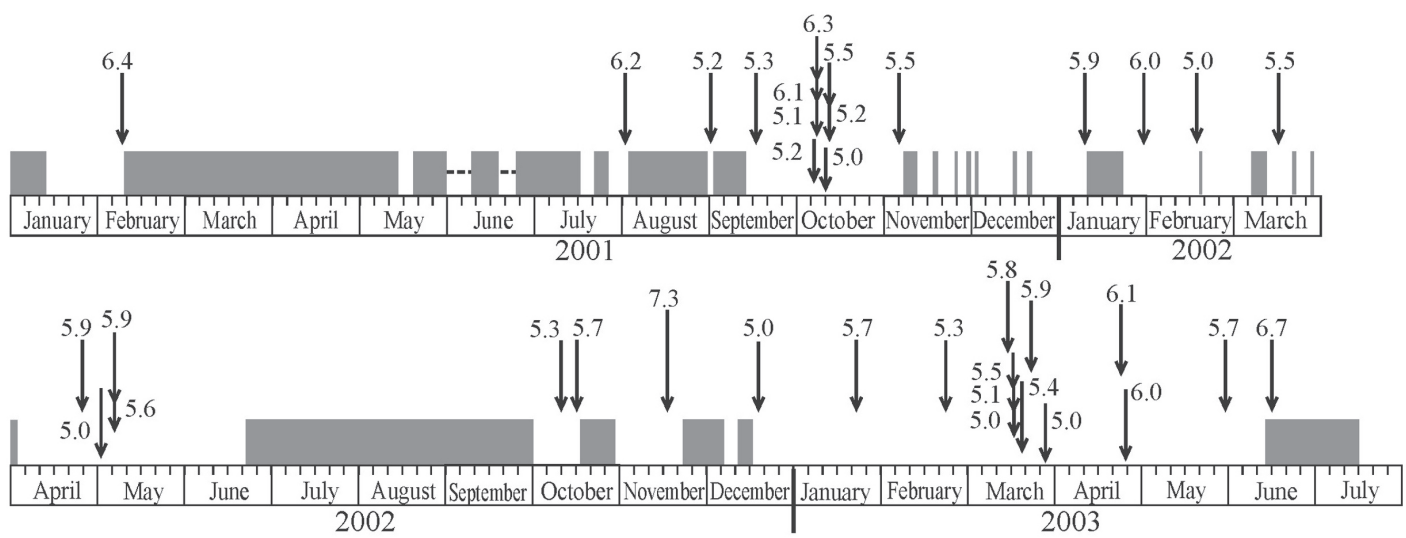

1

Fig. 7. The periods of presence/absence of diurnal variations of GAE versus times of major earthquakes occurrence: 1- presence of characteristic DGAED, 2-data gaps. The earthquakes with $\mathrm{M}_{\mathrm{LH}} \geq 5.0$ occurred at epicentral distances of $\mathrm{R} \leq 300 \mathrm{~km}$ from the base station and the earthquakes with $\mathrm{M}_{\mathrm{LH}} \geq 5.5$ occurred at epicentral distances of $\mathrm{R} \leq 550 \mathrm{~km}$. The earthquake of November 17, 2003, $\mathrm{M}_{\mathrm{w}}=7.3$ occurred at near1000 km epicentral distance. 
Table I. Earthquake's parameters, date January 1, 2001- July 31, 2003, location R $\leq 300 \mathrm{~km}, \mathrm{M}_{\mathrm{LH}} \geq 5.0$; location $\mathrm{R} \leq 550 \mathrm{~km}, \mathrm{M}_{\mathrm{LH}} \geq 5.5$; location $\left.\mathrm{R} \leq 1000 \mathrm{~km}, \mathrm{M}_{\mathrm{W}}>7.0\right)$ Note: $\mathrm{H}$ - earthquake depth; $\mathrm{R}$ - distance from epicenter to borehole G-1

\begin{tabular}{|c|c|c|c|c|c|c|}
\hline Earthquake No & Date & MLH & Lat.N & Long.E & $\mathbf{H}, \mathbf{k m}$ & $\mathbf{R}, \mathbf{k m}$ \\
\hline 010207 & 2001:02:07 & 6.4 & 52,28 & 153,66 & 476 & 346 \\
\hline 010802 & 2001:08:02 & 6.2 & 56,21 & 164,05 & 25 & 495 \\
\hline 010901 & 2001:09:01 & 5.2 & 53,92 & 159,75 & 134 & 120 \\
\hline 010917 & 2001:09:17 & 5.3 & 52,84 & 159,98 & 41 & 191 \\
\hline 011007 & 2001:10:07 & 5.2 & 52,39 & 160,67 & 2 & 153 \\
\hline $011008 \mathrm{a}$ & 2001:10:08 & 6,1 & 52,62 & 160,46 & 31 & 129 \\
\hline $011008 b$ & 2001:10:08 & 6.3 & 52,65 & 160,49 & 24 & 130 \\
\hline $011008 \mathrm{c}$ & 2001:10:08 & 5.1 & 52,5 & 160,59 & 15 & 142 \\
\hline 011009 & 2001:10:09 & 5.0 & 52,43 & 160,59 & 18 & 146 \\
\hline 011010a & 2001:10:10 & 5.5 & 52,51 & 160,57 & 17 & 141 \\
\hline $011010 \mathrm{~b}$ & 2001:10:10 & 5.2 & 52,46 & 160,72 & 8 & 152 \\
\hline 011103 & 2001:11:03 & 5.5 & 55,93 & 161,35 & 104 & 366 \\
\hline 020106 & 2002:01:06 & 5.9 & 48,67 & 155,09 & 40 & 543 \\
\hline 020128 & 2002:01:28 & 6.0 & 49,29 & 155,98 & 21 & 454 \\
\hline 020215 & 2002:02:15 & 5.0 & 52.12 & 159,89 & 18 & 130 \\
\hline 020315 & 2002:03:15 & 5.5 & 49,44 & 155,96 & 21 & 439 \\
\hline 020426 & 2002:04:26 & 5.9 & 53,36 & 160,99 & 57 & 160 \\
\hline 020503 & 2002:05:03 & 5.0 & 52,49 & 160,79 & 20 & 155 \\
\hline 020508a & 2002:05:08 & 5.6 & 52,22 & 160,44 & 32 & 150 \\
\hline $020508 b$ & 2002:05:08 & 5.9 & 53,73 & 160,93 & 35 & 170 \\
\hline 021008 & 2002:10:08 & 5.3 & 52,72 & 160,30 & 33 & 115 \\
\hline \multirow[t]{2}{*}{021016} & 2002:10:16 & 5.7 & 51,66 & 157,68 & 108 & 165 \\
\hline & 2002:11:17 & $\mathrm{M}_{\mathrm{W}}=7.3$ & 47.82 & 146.21 & 459 & 1050 \\
\hline 021218 & 2002:12:18 & 5.0 & 52,91 & 159,82 & 40 & 79 \\
\hline 030120 & 2003:01:20 & 5.7 & 49,06 & 155,88 & 54 & 480 \\
\hline 030221 & 2003:02:21 & 5.3 & 55,45 & 159,79 & 349 & 279 \\
\hline 030315 & 2003:03:15 & 5.8 & 52,15 & 160,66 & 4 & 166 \\
\hline $030317 \mathrm{a}$ & 2003:03:17 & 5.0 & 52,25 & 160,58 & 13 & 155 \\
\hline $030317 b$ & 2003:03:17 & 5.1 & 52,09 & 160,72 & 13 & 174 \\
\hline $030317 \mathrm{c}$ & 2003:03:17 & 5.5 & 52,26 & 160,54 & 32 & 153 \\
\hline 030318 & 2003:03:18 & 5.4 & 52,23 & 160,61 & 15 & 159 \\
\hline 030319 & 2003:03:19 & 5.9 & 52,16 & 160,85 & 48 & 176 \\
\hline 030325 & 2003:03:25 & 5.0 & 52,02 & 160,70 & 40 & 178 \\
\hline 030423 & 2003:04:23 & 6.1 & 55,98 & 163,44 & 20 & 450 \\
\hline 030424 & 2003:04:24 & 6.0 & 48,76 & 155,21 & 42 & 531 \\
\hline 030529 & 2003:05:29 & 5.7 & 50,65 & 157,53 & 40 & 274 \\
\hline 030616 & 2003:06:16 & 6.7 & 55,3 & 160,74 & 190 & 263 \\
\hline
\end{tabular}


Temporal intervals from the beginning of the «usual» DGAED perturbation until the time of the earthquake $\mathrm{M}_{\mathrm{LH}} \geq 5.0$ are in limited to $1 \div 25$ days. The relationship between noted temporal intervals and parameters of the earthquakes is still debated. This also concerns the recovery time for diurnal distribution after the earthquake occurred. Restoration of DGAED following the earthquakes takes several days in about $30 \%$ of all cases, but in some cases the recovery time was much greater.

It is worth mentioning that we considered several of limits on magnitude $\mathrm{M}_{\mathrm{LH}}$ and radius of epicentral zone R. We attempted to separate stronger earthquakes (occurring times to be compared with presence/absence of diurnal variations) and the flow of weak and moderate seismic events. On the other hand, we need a sufficient accumulation of strong events for the analysis. Enumeration of possibilities resulted in the optimal choice of above limits of magnitude $\mathrm{M}_{\mathrm{LH}}$ and radius $\mathrm{R}$. We selected two limiting values of $\mathrm{M}_{\mathrm{LH}}$ (5.0 and 5.5) and two corresponding values of $\mathrm{R}(300$ and $550 \mathrm{~km})$ for the sake of strong validity of the results. Our optimal choice of $\mathrm{M}_{\mathrm{LH}}$ and $\mathrm{R}$ limits allowed us to obtain the above relationship between GAE diurnal variations and the seismic process in the studied region. Another selection of these limits may modify the result represented in fig. 7. For example, reducing the $\mathrm{M}_{\mathrm{LH}}$ limit under condition of the same value of radius $R$ entails a growth of the number of earthquakes that occurred on the background of GAE diurnal variations.

In one case an earthquake occurred during a period of diurnal distribution restoration, when the time of DGAED disappearance ended. This does not contradict the fact that the disappearance of DGAED preceded the occurrence of all 37 earthquakes. But we prefer to consider this debatable case as unsuccessful event.

We estimated the probability of coincidence of anomalies of GAE observations (disorder of characteristic diurnal variations) and strong earthquake occurrence with the help of probability binomial distribution technique. The binomial distribution describes the probability $P(q, n, k)$ of occurrence of $k$ unsuccessful events in $n$ tests on conditions that the probability of successful result of individual test is (1-q):

$$
P(q, n, k)=\mathrm{C}_{\mathrm{n}}^{\mathrm{k}}(1-q)^{\mathrm{k}} q^{n-k},
$$

Where $C_{n}^{k}$ is a binomial coefficient which is determined by the formula $\mathrm{C}_{\mathrm{n}}^{\mathrm{k}}=n ! /(k !(n-k) !)$

To use (4) we associated the number $n$ of tests for GAE data with the number of strong earthquakes which occurred independently of one another during the time of observations. Some seismic swarms were recorded in the period October, 2001-March, 2003. Since shocks in a swarm were not independent events, we considered each swarm as a test (in the same manner as an ordinary earthquake). The total number of independent seismic events (tests) is $n=26$. Only one earthquake occurred when the characteristic diurnal variations were present (the date is June, 16 2003, see fig. 7). So, $k=1$ and the number of successful events is $(n-k)=$ 25 . A value of probability $q$ may be estimated as a ratio of time without GAE diurnal variations to total time of observations. In the case considered $q=0,4$.

The binomial distribution gives following numerical estimate of probability for noted value of parameters $q, n, k: P=1.8 \cdot 10^{-9}$. Such value of probability is very small compared to unity, and in comparison with the maximum of expression (3.4). It is well known that the expression of binomial distribution (3.4) reach maximum when $q=(n-k) / n$. In our case the maximum of (3.4) is approximately equal to $P_{\max } \approx 0.18$.

In a conditional case when all 37 earthquakes are independent, $n=37$, and $k=1$ the value of probability $P$ for the same $q$ is of order $10^{-14}$. So, the hypothesis is not valid that a disorder of characteristic diurnal variations and final phase of earthquake preparation is a random coincidence. One can deduce from the negligible probability of co-incidental correlation between GAE variations mode and times of strong seismic events that onset of GAE diurnal variations damping regularly precedes the possible occurrence of an earthquake.

\section{Discussion of a possible origin}

To study the correlation between DGAED and variations of averaged strength of natural electromagnetic (EM) field we carried out syn- 
chronous measurements of GAE and EM variations. An underground electric antenna was used for measurements of the vertical component of the natural electric field, $E_{\mathrm{N}}$. The perceptibility of the antenna whas reached with wire elements of more than $1 \mathrm{~km}$ length: a free conductor of multicore cable of the geophone and borehole casing. The parameters of electromagnetic measuring channels were identical with geoacoustical ones (the only difference is in the source of signals), measurements were carried out in the same frequency bands.

The measurements started in May 2003 at the same point (G-1 borehole). It is worth em- phasizing that we intended to involve just electromagnetic field because of following a priori reason. It is well-known that a temporal dependence of natural electric field (vertical component $E_{\mathrm{N}}$, in particular) has diurnal variations with nocturnal maxima and day time minima. This notion is based on studies of characteristics of radio noise and electromagnetic waves propagation in the frequency band $30 \mathrm{~Hz}-30$ kHz (Osinin, 1982; Remizov, 1985). Lightning discharges in remote world thunderstorms centers are the main sources of electromagnetic waves in noted frequency band at North- Eastern part of territory of Russia (Remizov, 1985).

GAE level,

$\mathrm{Z}, 160 \mathrm{~Hz}$

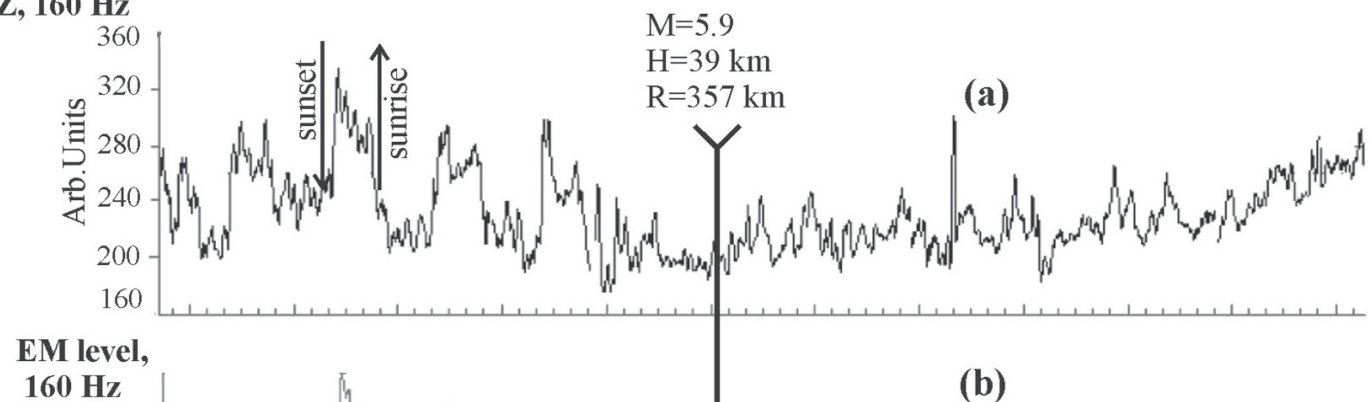

$160 \mathrm{~Hz}$
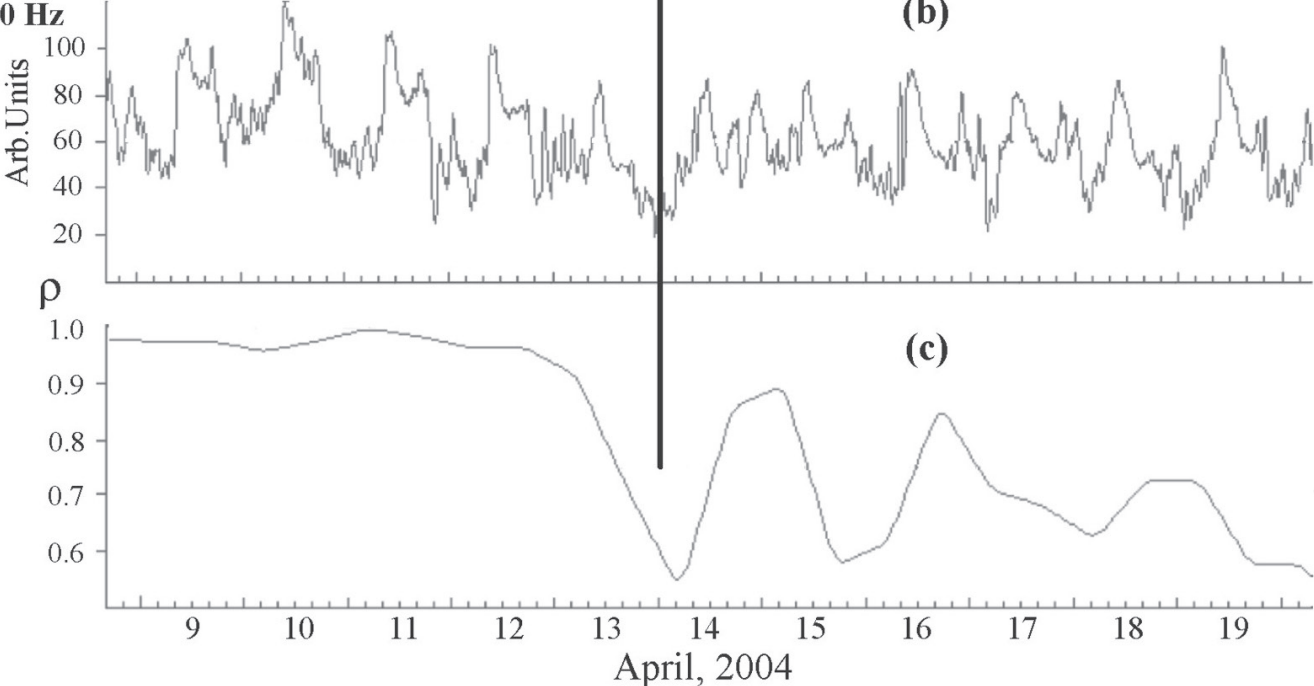

Fig. 8a-c. Results of simultaneous measurements of geoacoustic and electromagnetic temporal variations: a) GAE level measurements at $160 \mathrm{~Hz}$ frequency band ( $\mathrm{Z}$ component); b) EM field level measurements at the same frequency band; c) cross correlation coefficient $\rho$. The vertical line indicates earthquake moment. 
The day-night variations of ultra low frequency (ULF) electromagnetic field are pre-determined by daylight sharp deterioration of radio wave propagation condition in a waveguide between ionosphere and the Earth surface primarily due to lowering of ionosphere height resulted from daylight occurrence of D-layer at near $80 \mathrm{~km}$ height. In Kamchatka, ULF electromagnetic emission with explicit diurnal variations is caused mainly by lightning discharges in a remote world thunderstorm center, located on azimuth 190-255 degrees.

The results of simultaneous geoacoustic and electromagnetic measurements demonstrated that the variations of GAE level and electromagnetic ones were practically identical during periods when DGAED were steady. Meanwhile such periods coincided with aseismic time gaps. During these periods the cross correlation coefficient $\rho$ was of order of value $\rho=0.80 \div 0.99$. So, for instance $\rho=0.91 \div 0.99$ for interval of April 9-12, 2004, fig. 8; $\rho$ $=0.92 \div 0.93$ for interval of June 15-17, 2003, fig. 9. But, before strong earthquakes (a day or more) and during relaxation periods after the events the variations of GAE and of electromagnetic field became dissimilar: $\rho=0.53 \div 0.89$ for interval of April 13-19, 2004, fig. 8; $\rho$ $=0.001 \div 0.34$ for interval of May $28-$ June 09, 2003, fig. 9 .

It should be noted especially, that the strong correlation between results of GAE and natural

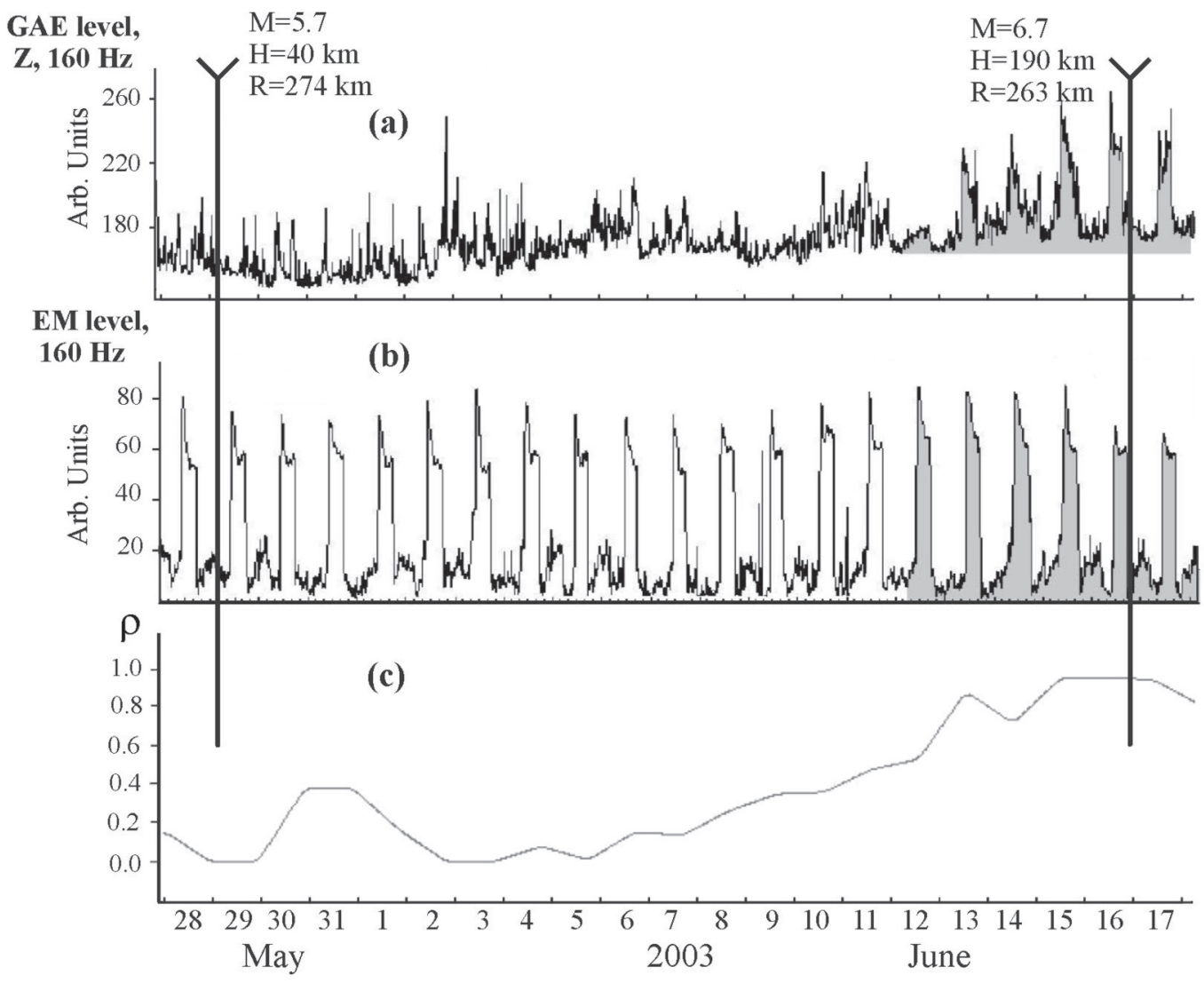

Fig. 9a-c. An example of resumption of day-night variations of mean GAE level: a,b,c- the same as on the fig. 8 . 
EM field measurements (in particular, synchronous diurnal variations in both signals) cannot be explained by electromagnetic noise induced by the environment. Non-instrumental origin of the observed effect may be verified by presented facts and considerations. Usually, electromagnetic noise collected by sensor input and/or transmission line (long cable), particularly the influence of the neighboring measuring line, is a constant, when the location of sensors and cables is fixed. But the results of simultaneous geoacoustic and electromagnetic measurements represented by fig. 8 demonstrate the change in GAE record, meanwhile the plot of natural electric field (vertical component) is without change. Diurnal variations of GAE disappeared rapidly (fig. 8a), and the correlation coefficient between GAE and EME series reduced. The dissimilar change in GAE was observed shortly before earthquake, but this aspect plays no role for the point of that how to check up the absence of noise induced by neighboring channel. Another example is given by fig. 9 , where the period from May 28 to June 11, 2003 is without GAE diurnal variations, thereafter the variations arise in interval June 12-17, 2003 and their amplitude increases gradually. But diurnal variations in the natural electromagnetic field (fig. 9b) are of the same amplitude during the period of May 28-June 17, 2003. This fact may be considered a solid argument that variations in output signals on GAE measuring channels do not interference induced by external electromagnetic field via sensor details or cable connecting the geophone with recording and processing units located at original ground. In the contrary case the amplitude of GAE diurnal variations should be steady throughout the period of observations.

Moreover, the temporal plots of horizontal and vertical component of GAE have quite a different form, although the frequency band is the same (Gavrilov et al., 2006). The constructive elements of both channels are identical. So the characteristics (such as shunt capacitance and mutual inductance to circuit of electromagnetic channel) are close, and they predetermine noise occurrence.

We checked this before geophone installation. Also, we reconnected geophone output to wires of the multicore cable to be sure that output signals of GAE depended on sensor only. This differs from features of induced noise which is sensitive to position of conductor (distance from wire to core screen).

Some closely related results of other works confirm the physical rather than instrumental origin of correlated diurnal changes in GAE and EM signals. For instance, a high degree of correlation of diurnal variations of GAE and electromagnetic field during the aseismic period is correlated with the result of (Paparo et al., 2002) where diurnal variations of AE level on bedrock outcroppings with maxima at local nighttime (similarly to GAE, see interval of April 9-12, 2004, fig. 8) were described.

The synchronization of increase/decrease of $\mathrm{AE}$ and of natural telluric electromagnetic field have been noted. Both temporal dependences can be characterized with a meander line. The similarity of daily distributions of GAE and AE which differ by frequency range and depths of sources speak in favour of the fact that this phenomenon is a manifestation of behavior of the loaded geological medium. No particular factor like bias of electric induction over long cable or thermal stress near bedrocks surface due to nighttime cooling (Paparo et al., 2002) is adequate for consistent explanation of those synchronized variations.

The comparison of results obtained by borehole GAE measurements with the results of laboratory experiments with loaded specimens exposed to electromagnetic field (Chelidze et al., 2002; Sobolev and Ponomarev, 2003; Il'ichev et al., 2003; Bogomolov et al., 2004; Zakupin et al., 2006a) has become the theory of a unified role of electric field for AE and GAE variations. According to the experiments referred above electromagnetic action over rock specimens which are tested by press driven compressive loads accompanied by appreciable growth of $\mathrm{AE}$ activity. The main feature of the revealed effect of $\mathrm{AE}$ electrostimulation is the temporary growth of averaged level of AE activity after short impact or during a session with enhanced electric strength, provided that the main compressive load is constant and its value is in the range from 0.7 up to 0.95 of disruption. This is the so-called AE response to electric 
power action, EPI, (Zakupin et al., 2006a; 2006b). Heuristically, such acoustic emission response to EPI seems to look similar to the effect of nighttime GAE level growth correlated to nocturnal enhancement of electric field level (the more value of natural electric field strength the more level of GAE in the same frequency band). Our approach to unified consideration of laboratory and full-scale survey results is based on the similarity of stressed state of embedded rocks and laboratory tested ones. Actually, AE responses were recorded on specimens when the main compression stress was in the range 20 - $100 \mathrm{MPa}$. A tectonic stress at nearly one $\mathrm{km}$ depth is of the same order of magnitude (Kropotkin et al., 1987).

But a difficult point for the hypothesis of electric stimulation of nighttime GAE level (resulting in the modulation) arises during quantitative estimates of strength of natural electric field and that applied in laboratories. Quantitative estimates to analyze the observed modulation of GAE level by natural electromagnetic emission of the Earth are as follows. According to reference (Remizov, 1985), the maximal value of the electric component of the EM field measured on Earth surface, over the whole frequency band may be evaluated as $0.45 \div 1.0 \mathrm{mV} / \mathrm{m}$. The damping of electric component at $1 \mathrm{~km}$ depth, calculated for $160 \mathrm{~Hz}$ and the soil of moderate moisture (the conductivity is about $\left.\sigma=0.01(\mathrm{Ohm} \times \mathrm{m})^{-1}\right)$ is near $9 \mathrm{db}$. Hence, the amplitude of electric field strength at the depth of geophone location can not exceed $0.16 \div 0.36 \mathrm{mV} / \mathrm{m}$. Measurements in other boreholes and in other regions are required to establish that correlated diurnal changes in GAE are a general effect (although the mechanism of electric- geoacoustic conversion is not clear completely). Alternatively they may be caused by specific oversensitivity of GAE sources located in the vicinity of the geophone at the point of G-1 borehole.

\section{Summary}

Continuous geoacoustic measurements in deep boreholes with high-sensitivity geophones are an effective method of monitoring stressed- strained geological medium. Deepening of the geophone at $1000 \mathrm{~m}$ depth in borehole at Petropavlovsk-Kamchatsky reduced the level of anthropogenic noise by two orders of magnitude in the band of $30 \mathrm{~Hz}$ central frequency, and reduced it almost by an order of magnitude in the $160 \mathrm{~Hz}$ band. Furthermore, increasing the depth of measurements has practically eliminated the bias of meteorological factors on measurements of the vertical component of GAE signals. New GAE measurements have revealed diurnal temporal distribution of GAE level in bands with central frequencies 30 and $160 \mathrm{~Hz}$. Diurnal distribution of GAE is presumably related to daily variations of the level of electromagnetic field strength in Earth's crust. The loss or damping of geoacoustic day-night variations (provided continued diurnal variations in natural electric field) appears to indicate changes in stressed-strained state of the geological medium which allow a considerable growth of probability of strong earthquake occurrence. A generalized sequence of obtained results is proposed as a precursor of «short-term aseismicity»; an indicator that no strong earthquakes are likely to occur in a circular $(300 \mathrm{~km}$ radius) area around the observational point, during a period of robust presence of GAE diurnal variations, as long as a disorder of GAE mode terminates such period. This important principle (precursory statement) may be used for recognition and/or reliable predictions of temporal intervals, when the probability of strong earthquake occurrence in a limited area is very low (at least, for Kamchatkan region and North Kuriles islands).

\section{Acknowledgements}

This research was partially supported by the RFBR (grants 06-06-05-96071 and 07-0500687) and FEB RAS (the project 06-III-A-08-327).

\section{REFERENCES}

Belyakov, A.S., A.G. Gamburtsev, V.S. Lavrov, A.V. NiKOlAEV and N.K. PrivalovsKiI (1996): Vibration Action on Rocks and Their Induced Seismic Emission, 
Fizika Zemli (Solid Earth Phys.), 32 (2), 68-74.

Belyakov, A.S., A.G. Gamburtsev, V.S. LaVrov, A.V. NiKOLAEV and L.L. KHUDZINSKII (1999): Underground Acoustic Noise and Its Relation to Tidal Deformations, Ibid, 35 (12), 1002-1009.

BelyaKov, A.S.(2000): Magnetoelastic acoustic geophones for geophysical research, Seismic equipment (UIPE RAS, Moscow), Book 33, 27-45.

Bogomolov, L.M., P.V. IL'ICHEV, V.A. NovikOV, V.I. OKUNEV, V.N. SyCHEV, A.S. ZAKUPIN (2004): Acoustic emission response of rocks to electric power action as seismicelectric effect manifestation, Annals of Geophysics, 47 (1), 65-72.

Chelidze, T., N. NoVaramashvili, M. Devidze, Z. TcheLIDZE, V. CHIKHLADZE and T. MATCHARASHVILI (2002): Laboratory study of electromagnetic initiation of slip, Annals of Geophysics, 45 (5), 587-598.

Chelidze, T., T. Matcharashvili, J. Gogiashvili, O. LuRSMANASHVILI and M. DevidZE (2005): Phase synchronization of slip in laboratory slider system, Nonlinear Processes Geophys., 12, 1-8.

Cuomo, V., V. Lapenna, M. Macchiato, I. Marson, G. Paparo, D. Patella and S. Piscitelli (2000): Geolectrical and acoustical anomalous signals compared with seismicity in a test side of southern Apennines (Italy), Phys. Chem. Earth. (A), 25 (3), 255-261.

Diakonov, B.P., B. S. Karryev, O.B. Khavroshin, A.V. Nikolaev, L.N. Rykunov, R.R. Seroglasov, A.K. TrojanOV and V.V. TsiplaKov (1990): Manifestation of earth deformation processes by high-frequency seismic noise characteristics, Phys. Earth and Planet. Inter., 63, 151-162.

Gavrilov, V. A., Yu.V. Morozova and A.V. Storcheus (2006): Variations in the Level of Geoacoustic Emission in Deep Well G-1, Kamchatka and Their Relation to Seismicity, Volcanology and seismology, (1), 52-67.

GAVRILOV, V. A. (2007): Physical Causes of Diurnal Variations in the Geoacoustic Emission Level, Doklady RAN, Earth Sciences, 414, (4), 638-641.

Gorbatikov, A.V., O.A. Molchanov, M. Hayakava, S. UYEDA, et al. (2001): Acoustic Emission Before and After Earthquakes, Volcanology and seismology, (4), 66-78.
Gregori, G.P., G. PAPARO, U. CopPA and I. MARSON (2002): Acoustic Emission in geophysics: a reminder about the methods of analysis, Bull. Geophys. Teor. Appl., 43 (12), 157-172.

IL'icheV, P.V., A.V. Alad'ev, L.M. Bogomolov, V.N. SyCHEV et al. (2003): Parameters of acoustic emission signals initiated by electric action over loaded specimens, in Geodynamics and geoenvironmental problems of high-mountain regions, edited by S.V. GOLDIN and YU.G. LeONOV (Printhouse, Moscow-Bishkek), pp. 286-303.

Kropotkin, P.N., V.N. EFREMOV and V.M. MAKEEV (1987): Stressed state of Earth Crust and Geodynamics, Geotectonics, (1), 3-24.

OsININ, V.F. (1982): Radio noise from natural sources in the East of the USSR (Nauka, Moscow), pp. 161 (in Russian).

Paparo, G., G.P. Gregori, U. Coppa, R. De Ritis and A. TAloni (2002): Acoustic Emission (AE) as a diagnostics tool in geophysics, Annals of Geophysics, 45 (2), 401-416.

REMIZOV, L.T. (1985): Natural radio-interference (Nauka, Moscow), pp. 198 (in Russian).

RykunOv, A.L. and V.B. Smirnov(1985): Variations of the seismicity under effect lunar-solar and tidal deformations, Fizika Zemli (Solid Earth Phys.), 21 (1), 97-103.

Scheidegger, A.E. (1975): Physical aspects of natural catastrophes, (Elsevier Scientific, Amsterdam), pp. 289.

Sobolev, G.A. and A.V. Ponomarev (2003): Physics of earthquakes and precursor, (Nauka, Moscow), pp. 270.

Zakupin, A.S., A.A. Avagimov and L.M. Bogomolov (2006a): Responses of Acoustic Emission in Geomaterials to the Action of Electric Pulses under Various Values of the Compressive Load, Physics of the Solid Earth, (10), 43-50.

Zakupin, A.S., A.V. Alad'ev, L.M. Bogomolov, V.N. Sychev et al. (2006b): Interrelation of electric polarization and acoustic emission of terrestrial materials specimens under conditions of uniaxial compression, Volcanology and seismology, (6), 22-33. 